\title{
Properties of Matrix using Diatomite Based on Blast Furnace Slag
}

\author{
Sang-Soo, Lee, Dae-Yeon, Kim
}

\begin{abstract}
Recently, we have experimented to reduce fine dust which is a problem in the world. Fine dust is known to cause various diseases in the human body. Diatomite with adsorption characteristics was used to reduce fine dust, which is a source of indoor air pollution. As a binder, blast furnace slag and a circulating fluidized bed combustion boiler fly ash were used to replace cement. The assessment items are flexural strength, compressive strength, flow ability, density, water absorption, fine dust concentration. As the replacement ratio of diatomite increases, the density decreases and the water absorption tends to increase. It is considered that this is due to the porous property of diatomite. Flowability decreased with increasing diatomite replacement ratio. As the replacement ratio of diatomite increased, the amount of air content to increase. As the replacement ratio of diatomite increased, the adsorption performance per minute of fine dust increased. This is because the amount of fine dust adsorbed per specific surface area increased as the replacement ratio of diatomite having porous properties increased. If additional experiments are done and used for finishing materials, it will contribute to the improvement of indoor air quality.
\end{abstract}

Keywords : Fine dust, Diatomite, Circulating fluidized bed combustion boiler fly ash, Blast furnace slag, Adsorption, Indoor air quality

\section{INTRODUCTION}

Recently, the fine dust that is emerging as a global problem is smaller than $10 \mu \mathrm{m}$ and larger than $2.5 \mu \mathrm{m}$, and it mainly occurs on roadsides and industrial complexes[1]. Fine dust has many dangers to cause illness in humans, and the International Agency for Research on Cancer (IARC) classified it as a Group 1 carcinogen[2]. The Korea Centers for Disease Control and Prevention reported that the rate of hospitalization for chronic obstructive pulmonary disease (COPD) increased by $2.7 \%$ and mortality increased by $1.1 \%$ every $10 \mu \mathrm{g} / \mathrm{m}^{3}$ increase of fine dust (PM 10) concentration and the incidence of lung cancer increases by $9.0 \%$ every 10 $\mu \mathrm{g} / \mathrm{m}^{3}$ increase of fine dust (PM 2.5). In addition, allergic conjunctivitis, keratitis, rhinitis, bronchitis, asthma, lung cancer and many other diseases are caused[3][4][5][6][7].

The fourth industrial revolution has increased telecommuting and indoor living, indoor air quality is an important factor affecting the human body. Natural ventilation in the room, forced ventilation, and Infiltration phenomenon between windows and building gaps inevitably

Revised Manuscript Received on July 22, 2019.

* Correspondence Author

Sang-Soo Lee*, Dept of Architectural Engineering, Hanbat National

University, Daejeon, Korea Email: sslee111@ hanbat.ac.kr

Dae-yeon Kim, Dept of Architectural Engineering, Hanbat National

University, Daejeon, Korea Email: anrmrd11 @naver.com

occur, so that fine dusts in the air can enter the room[8]. Therefore, it is necessary to improve indoor air quality because indoor air pollution is intensified. This study informs about the danger of fine dust and aims to absorb and reduce fine dust in the air by making matrixes using absorbent materials.

\section{MATERIALS}

\section{A. Diatomite}

The diatomite is composed of silicic acid $\left(\mathrm{SiO}_{2}\right)$, and its color is white or grayish white. Weight is light. Because of its fine porosity, it has strong absorbency. Diatomite is a super porous body with many pores. It adsorbs and decomposes harmful substances due to the micropores inside the silica. Adsorption of diatomite is generally carried out by collecting the adsorbent material on the surface of the adsorbent material, and the adsorbent material is adsorbed into the diatomite by physical adsorption properties. Diatomite has the ability to maintain humidity and remove odors. The use of diatomite, which has a lot of voids, will be helpful for physically adsorbing fine dust. Diatomite has a typical particle size of 50 to $100(\mu \mathrm{m})$. The density of the diatomite used in this study was $2.22 \mathrm{~g} / \mathrm{cm}^{3}$ and the fineness was $4,125 \mathrm{~cm}^{2} / \mathrm{g}$. [Table 1] shows the chemical composition of the diatomite. [Fig. 1] is a photograph of diatomite. [Fig. 2] shows the SEM of diatomite.

Table 1. Chemical composition of diatomite

\begin{tabular}{|l|l|l|l|l|l|}
\hline \multicolumn{7}{|c|}{ Chemical composition $(\%)$} \\
\hline & $\mathrm{SiO}_{2}$ & $\mathrm{Al}_{2} \mathrm{O}_{3}$ & $\mathrm{CaO}$ & $\mathrm{MgO}$ & $\mathrm{Fe}_{2} \mathrm{O}_{3}$ \\
\hline $\mathrm{D}$ & 89.50 & 4.10 & 0.60 & 0.30 & 1.50 \\
\hline
\end{tabular}
$\mathrm{D}=$ Diatomite

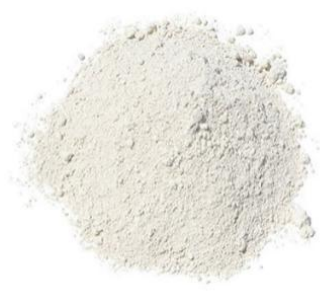

Fig. 1. Diatomite

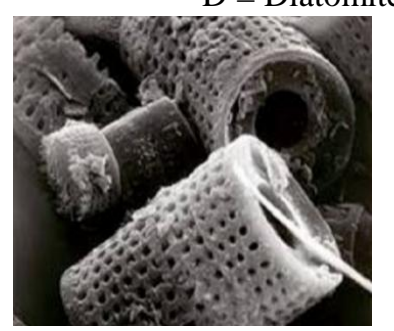

Fig. 2. SEM of diatomite

\section{B. Circulating fluidized bed combustion boiler fly ash}

The circulating fluidized bed combustion boiler fly ash used in this study is an improvement of the circulating fluidized bed combustion boiler fly ash discharged from the circulating fluidized bed combustion boiler.

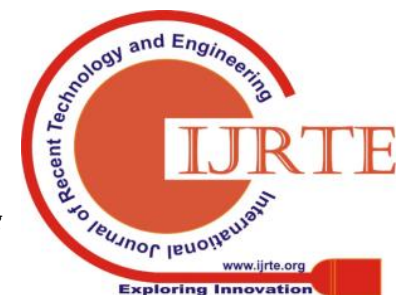


A density of $2.57 \mathrm{~g} / \mathrm{cm}^{3}$, and a fineness of $2,573 \mathrm{~cm}^{2} / \mathrm{g}$. [Table 2] shows the chemical composition of the circulating fluidized bed combustion boiler fly ash. [Fig. 3] is a photograph of a circulating fluidized bed fly ash. [Fig. 4] shows the SEM of the circulating fluidized bed fly ash

Table 2. Chemical composition of circulating fluidized bed combustion boiler fly ash

\begin{tabular}{|c|c|c|c|c|c|c|}
\hline \multicolumn{7}{|c|}{ Chemical composition $(\%)$} \\
\hline & $\mathrm{SiO}_{2}$ & $\mathrm{Al}_{2} \mathrm{O}_{3}$ & $\mathrm{Fe}_{2} \mathrm{O}_{3}$ & $\mathrm{CaO}$ & $\mathrm{MgO}$ & $\mathrm{SO}_{3}$ \\
\hline $\mathrm{CBF}$ & 10.45 & 7.17 & 1.80 & 15.87 & 55.31 & 1.97 \\
\hline
\end{tabular}
$\mathrm{CBF}=$ Circulating fluidized bed combustion boiler fly ash

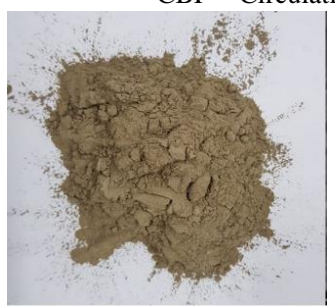

Fig. 3. Circulating fluidized bed combustion boiler fly ash

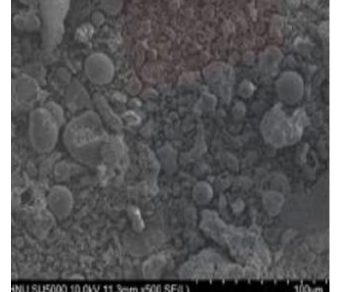

Fig. 4. SEM of circulating fluidized bed combustion boiler fly ash

\section{Blast furnace slag}

The blast furnace slag used in this study had a density of $2.91 \mathrm{~g} / \mathrm{cm}^{3}$ and a fineness of $4,464 \mathrm{~cm}^{2} / \mathrm{g}$. The chemical composition was $52.6 \% \mathrm{CaO}$ and $28.7 \% \mathrm{SiO}_{2}$. It represents the largest composition ratio. [Table 3] shows the chemical composition of the blast furnace slag. Blast furnace slag is a blast furnace slag blast furnace slag which is rapidly cooled by spraying water into a hot molten slag. In 1862, Langer of Germany started to recycle slag, which is an industrial byproduct, by adding slaked lime. The blast furnace slag, which was dried in 1953, was crushed to produce fine powder having a surface area very similar to that of modern slag powder. [Fig. 5] is a photograph of blast furnace slag powder. [Fig. 6] shows the SEM of blast furnace slag powder.

Table 3. Chemical composition of blast furnace slag
Fig. 5. Blast furnace slag powder

\begin{tabular}{|c|c|c|c|}
\hline \multicolumn{3}{c}{ Chemical com } \\
\hline & $\mathrm{SiO}_{2}$ & $\mathrm{Al}_{2} \mathrm{O}_{3}$ & $\mathrm{Fe}_{2} \mathrm{O}$ \\
\hline $\mathrm{BFS}$ & 28.7 & 9.5 & 0.6 \\
\hline & & \\
& & \\
& &
\end{tabular}

fly ash was fixed at $50 \%$. W/B was fixed at $65 \%$. The replacement ratio of diatomite was changed to $10,20,30$, $40 \%$.

Table 4. Experimental factors and level according to replacement ratio of diatomite

\begin{tabular}{|c|c|c|}
\hline $\begin{array}{c}\text { Experimental } \\
\text { factor }\end{array}$ & Experimental level & Note \\
\hline Binder & BFS, CBF & 2 \\
\hline $\begin{array}{c}\text { D replacement } \\
\text { ratio }\end{array}$ & $10,20,30,40(\%)$ & 4 \\
\hline W/B & 65 (wt.\%) & 1 \\
\hline $\begin{array}{c}\text { Curing } \\
\text { conditions }\end{array}$ & $\begin{array}{c}\text { Constant temperature and } \\
\text { humidity curing } \\
\left.\text { (temp.20 } 2{ }^{\circ} \text { C hum.80 } \pm 5 \%\right)\end{array}$ & 1 \\
\hline $\begin{array}{c}\text { Assessment } \\
\text { items }\end{array}$ & $\begin{array}{c}\text { Flexural strength, Compressive } \\
\text { strength, Air content, lowability, } \\
\text { Density, Water absorption, Fine } \\
\text { dust concentration }\end{array}$ & 7 \\
\hline
\end{tabular}

\section{EXPERIMENTAL METHOD}

\section{A. Fine dust concentration}

Since there is no clear method for measuring the concentration of fine dust in Korea, the experiment was conducted based on the measurement method of indoor fine dust concentration proposed by Hanbat National University[9][10]. Fine dust particles, adsorbent-based cured products, a fan and a fine dust meter were placed in a closed chamber. Fine dust moving in the chamber by the wind of the fan and finally reaches the surface of the cured body. The fine dust adsorption matrix was set to $40 \times 40 \times 160(\mathrm{~mm})$ in accordance with 'KS L ISO 679'.

\section{B. Mixing method}

In this experiment, used concrete single axial spiral mixer, powder was mixed with 40 RPM for 90 seconds, mixed with water at 45 RPM for 90 seconds.

\section{Specimen production}

The paste specimens used in the experiment were made according to 'KS L ISO 679' 'Test Method for Cement Strength` and $40 \times 40 \times 160 \mathrm{~mm}$ rectangular specimens were used as test specimens.

\section{Flexural strength and compressive strength}

The flexural strength test and compressive strength test were carried out according to 'KS L ISO 679' 'Test Method for Cement Strength'.

\section{E. Density}

Specimens were fabricated using $\Phi 100 \times 200(\mathrm{~mm})$ cylinder mold to measure density and absorptivity. After demolding the hardened specimen, measure the mass of the specimen, measure the density, calculate the volume of the specimen, and then divide the mass by volume.

\section{A. Experimental plan according to replacement ratio of diatomite}

This is an experiment to evaluate the performance of the fine dust adsorbed matrix using diatomite. Based on the results of previous experiments, the replacement ratio of blast furnace slag and circulating fluidized bed combustion boiler






\section{F. Water absorption}

In order to measure the water absorption, the specimen is demolded and the specimen weight (W1) is measured. The specimen is then dried in the dryer for 24 hours and the specimen weight (W2) in absolute dry condition is measured. Subtract W2 from W1, divide the value by W2, and add 100 .

\section{G. Flowability}

In order to confirm the fresh state properties of the paste, the flowability test was performed with reference to KS L 5111 "Flow Table for Hydraulic Cement Test" non-strike measurement.

\section{H. Air content}

To measure the amount of air, it was carried out according to KS L 3136 "Method of measuring the air quantity of hydraulic cement mortar".

\section{EXPERIMENTAL RESULTS AND ANALYSIS}

\section{A. Density and water absorption}

[Fig. 7] and [Fig. 8] is a graph showing density and water absorption according to replacement ratio of diatomite. As the replacement ratio of diatomite increased, the density tended to decrease and the absorption ratio tended to increase. The highest density was observed at a replacement ratio of diatomite of $10 \%$ to $1.59 \mathrm{~g} / \mathrm{cm}^{3}$. And the density was the lowest at a replacement ratio of $40 \%$ to $1.46 \mathrm{~g} / \mathrm{cm}^{3}$. At the replacement ratio of $40 \%$, the absorption rate was the highest at $36.2 \%$. The rate of absorption was $10 \%$ to $30.6 \%$. It is considered that this is due to the porous property of diatomite.

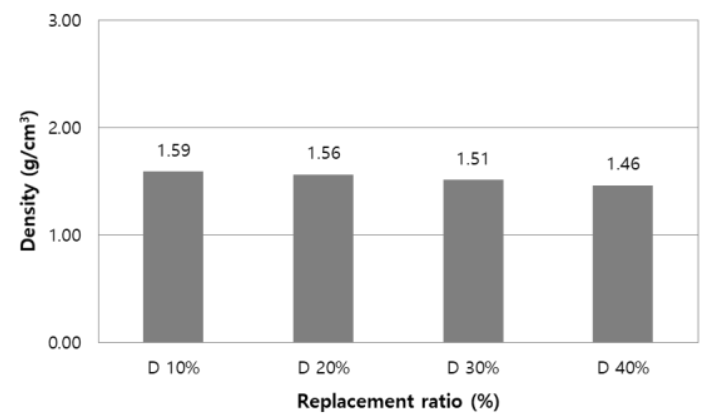

Fig. 7. Density according to replacement ratio of diatomite

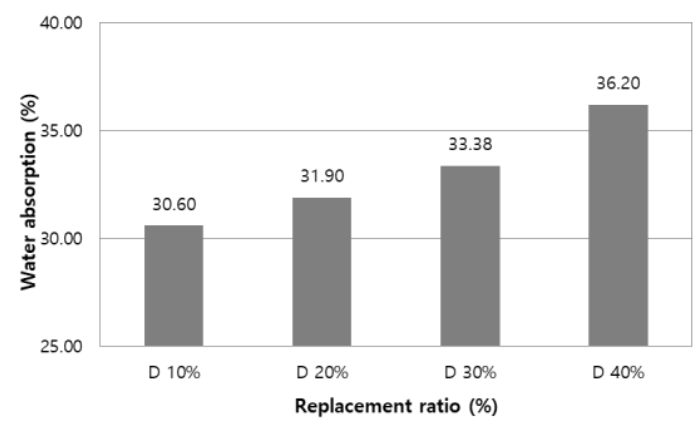

Fig. 8. Water absorption according to replacement ratio of diatomite

\section{B. Flowability}

[Fig. 9] shows the measurement results of flowability with replacement ratio of diatomite. As the replacement ratio of diatomite increases, the fluidity tends to decrease as a whole. It is considered that as the replacement ratio increases due to the porous property of diatomite, the fluidity decreases due to absorption of the water content. The fluidity is the highest at the replacement ratio of diatomite of $10 \%$ to $238 \mathrm{~mm}$, and the lowest value at the replacement ratio of diatomite of $40 \%$ to $195 \mathrm{~mm}$.

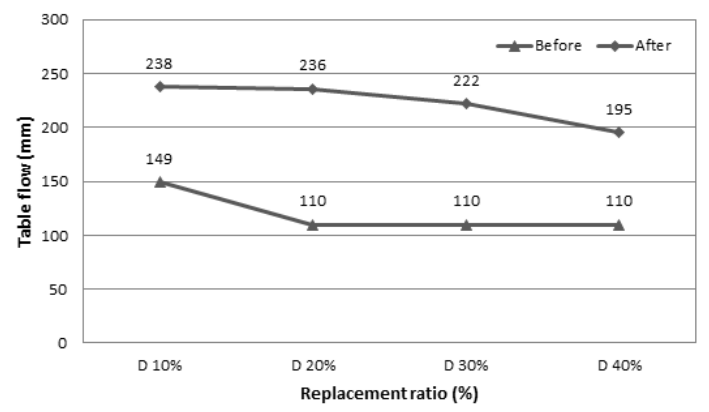

Fig. 9. Flowability according to replacement ratio of diatomite

\section{Air content}

[Fig. 10] shows the measurement results of air content according to the replacement ratio of diatomite. As the replacement ratio of diatomite increases, the amount of air tends to increase. It is considered that the amount of air in the paste is increased as the replacement ratio of diatomite as the porous material is increased. It is judged that the amount of air is increased as the fluidity is lowered by absorbing the compounding water into the particles. The replacement ratio of diatomite is the lowest at $10 \%$ to $1.2 \%$, and the highest value of replacement ratio of diatomite is $40 \%$ to $4.8 \%$.

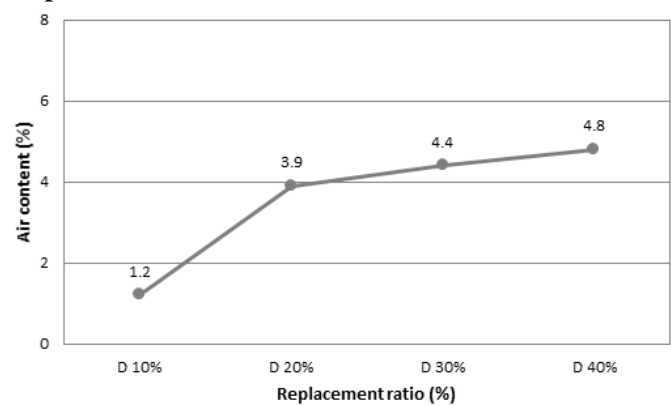

Fig. 10 Air content according to replacement ratio of diatomite

\section{Flexural strength and compressive strength}

[Fig. 11] and [Fig.12] show the strength measurements according to the replacement ratio of diatomite. As the replacement ratio of diatomite increases, the flexural strength tends to decrease. It is considered that the strength decreases as the replacement ratio increases due to the porous properties of diatomite. It has the highest value at $10 \%$ of replacement ratio of diatomite and 3.0 $\mathrm{MPa}$ at 28 days, and the lowest value at 28 days strength at $1.8 \mathrm{MPa}$ at $40 \%$ replacement ratio of diatomite. Compressive strength also tends to decrease with increasing replacement ratio of diatomite. It has the highest value of $6.8 \mathrm{MPa}$ at 28 days strength at the diatomite replacement ratio of $10 \%$ and lowest value at 28 days strength of $5.2 \mathrm{MPa}$ at $40 \%$ replacement ratio of diatomite.

Published By: 


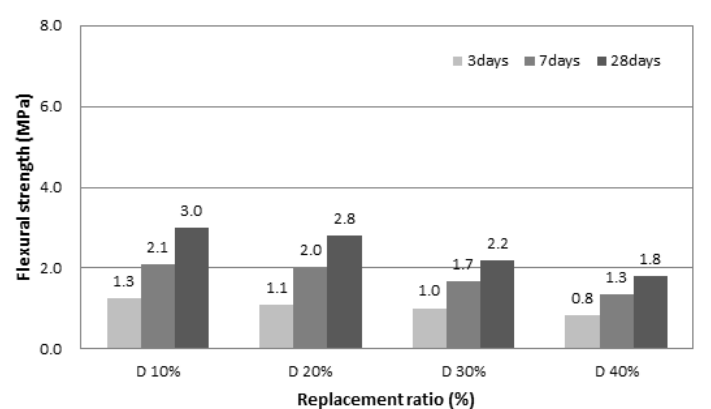

Fig. 11. Flexural strength according to replacement ratio of diatomite



Fig.12. Compressive strength according to replacement ratio of diatomite

\section{E. Fine dust concentration}

[Fig.13] is the result of PM10 fine dust concentration according to replacement ratio of diatomite. Based on the proposed measurement method of indoor dust density, fine dust, fan and fine dust measuring instrument were placed in a closed chamber and measured. As the replacement ratio of diatomite increases, the adsorption performance per minute of fine dust tends to be improved.

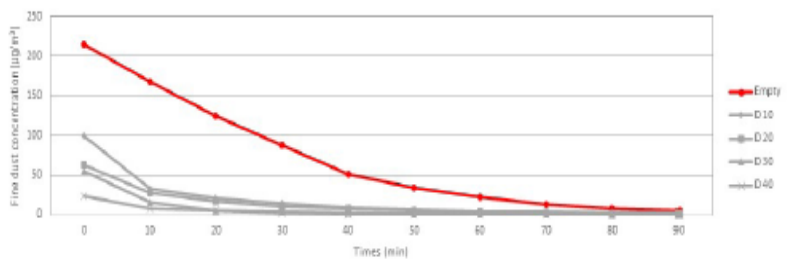

Fig. 13. Fine dust concentration of matrix according to replacement ratio of diatomite

[Fig. 14] is the result of PM2.5 fine dust concentration according to replacement ratio of diatomite. The adsorption performance of PM2.5 was also improved by increasing the replacement ratio of diatomite. This is considered to be due to the increase of the amount of fine dust absorption per specific surface area as the replacement ratio of the diatomite having the porous property increases, and it is considered that the diatomite can adsorb and reduce the fine dust particles.

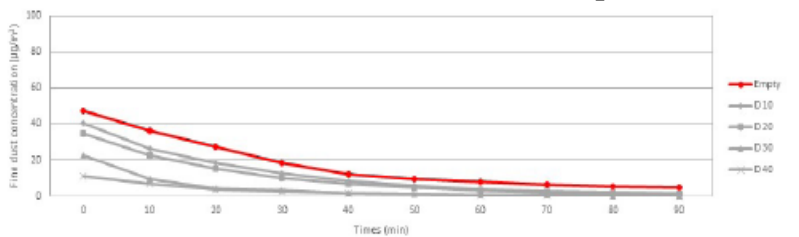

Fig. 14. Fine dust concentration of matrix according to replacement ratio of diatomite

\section{CONCLUSION}

In this paper, an experiment was conducted to evaluate the physical properties and the fine dust adsorption performance using diatomite. Blast furnace slag was used to reduce the use of cement to generate large amounts of $\mathrm{CO}_{2}$. As a method for adsorbing and reducing fine dust, which is a global problem, matrix was manufactured using diatomite, which is an adsorbent, and its characteristics were analyzed. the results are as follow.

1) As the replacement ratio of diatomite increases, the density decreases and the water absorption tends to increase. It is considered that this is due to the porous property of diatomite.

2) Flowability decreased with increasing replacement ratio of diatomite.

3) As the replacement ratio of diatomite increased, the amount of air content to increase.

4) As the replacement ratio of diatomite increased, the adsorption performance per minute of fine dust increased. This is because the amount of fine dust adsorbed per specific surface area increased as the replacement ratio of diatomite having porous properties increased.

If additional experiments are conducted and used for finishing materials, it will contribute to the improvement of indoor air quality.

\section{ACKNOWLEDGMENT}

This article was performance by the research grant of 2018 Korea Scientific Research Foundation [Project No. 2018R1A2B6006764].

\section{REFERENCES}

1. H. W. Park, Y. M. Jo "Regulation Standard of Fine Particles and Control Techniques of Emission Sources" Journal of Korean Society for Atmospheric Environment. 29(4), 486-503, 2013. http://dx.doi.org/10.5572/KOSAE.2013.29.4.486

2. K Straif, A Cohen, J Samet, Air Pollution and Cancer IARC Scientific publication No. 161, 2017.

3. D. Y. Kim, E. A . Jin, "The effects of air pollution (fine dust) on happiness and its monetary value" Journal of Korea Planning Association, 53(4), 205-219, 2018. https://doi.org/10.17208/jkpa.2018.08.53.4.205

4. H. R. Anderson, "Air pollution and mortality: A history" Atmospheric $\begin{array}{lll}\text { environment. } & 43(1), & 142-152,\end{array}$ https://doi.org/10.1016/j.atmosenv.2008.09.026

5. E. J. Park. "Health Risk Assessment of Fine Particles and Their Hazardous Chemicals" Ph.D Thesis, Dongduk womens university, 2008.

6. J. I. Choe, Y. S. Lee, "A Study on the Impact of PM2.5 Emissions on Respiratory Diseases" Journal of Environmental Policy and Administration.23(4) 155-172, 2015 http://dx.doi.org/10.15301/jepa.2015.23.4.155

7. K. H. Ha, M. N. Suh, D. Y. Kang, H. C. Kim, DC. Shin, CS. Kim, "Ambient Particulate Matter and the Risk of Deaths from Cardiovascular and Cerebrovascular Disease" Clinical Hypertension. 17(2), 74-83, 2011. http://dx.doi.org/10.5646/jksh.2011.17.2.74

8. J. M. Back, S. W. Yee, B. H. Lee, D. H. Kang, M. S. Yeo, K. W. Kim, “A Study on the relationship between the indoor and outdoor particulate matter concentration by infiltration in the winter" Journal of the architectural institute of korea planning \& design. 31(9), 137-144, 2015 http://dx.doi.org/10.5659/JAIK PD.2015.31.9.137 
9. S. M. O, "Properties of Eco-Friendly Mortar using Adsorbent to reduce Harmful Gas" master's thesis, Hanbat National University, 2016.

10. K. H. Kim "Properties of radon-reducing cement matrix using adsorbents" master's thesis, Hanbat National University, 2018.

\section{AUTHORS PROFILE}

Sang-Soo, Lee, Professor, Department of Architectural Engineering, Hanbat National University, Daejeon, Korea

Dae-Yeon, Kim, The master's course Department of Architectural Engineering, Hanbat National University, Daejeon, Korea 